\title{
Comportamento ingestivo de vacas lactantes alimentadas com diferentes teores de lipídeos na dieta
}

\author{
[Ingestive behavior of lactating dairy cows fed diets with different lipid contents]
}

\section{"Artigo Científico/Scientific Article"}

\author{
Alan Soares Machado ${ }^{1 *}$, Marcos Barcellos Café2 ${ }^{2}$, Marcelo Marcondes Godoy ${ }^{1}$, Anderli Divina \\ Ferreira Rios ${ }^{2}$, Aldi Fernandes Souza França $^{2}$, Emizael Menezes Almeida ${ }^{3}$, Douglas Dijkstra ${ }^{1}$, \\ Antônio Roberto Oliveira Júnior ${ }^{1}$, Lidiane Oliveira Silva ${ }^{1}$, Fagner Machado Ribeiro ${ }^{4}$
}

\author{
${ }^{1}$ Instituto Federal Goiano, Câmpus Ceres, Ceres-GO, Brasil. \\ ${ }^{2}$ Universidade Federal de Goiás, Goiânia-GO, Brasil. \\ ${ }^{3}$ Doutorando em Ciência Animal, Universidade Federal de Mato Grosso do Sul, Campo Grande-MS, Brasil. \\ ${ }^{4}$ Instituto Federal Goiano, Câmpus Rio Verde, Rio Verde-GO, Brasil. \\ *Autor para correspondência/Corresponding author: E-mail: asm3201@ @otmail.com
}

\begin{abstract}
Resumo
Objetivou-se, com este estudo, avaliar a inclusão do gérmen integral de milho (GIM) em substituição ao grão de milho moído na dieta de vacas lactantes, sobre o comportamento ingestivo, o tamanho médio das partículas e da fração não degradável. Foram utilizadas cinco vacas leiteiras, fistuladas no rúmen, multíparas, com aproximadamente 100 dias de lactação, com peso corporal médio de $490 \mathrm{~kg}$. Os tratamentos foram: 0,0; 6,7; 13,5; 20,1 e 26,9\% de GIM em substituição ao grão de milho moído. O delineamento experimental utilizado foi quadrado latino 5 x 5 . Foram cinco períodos de 21 dias cada, sendo 13 dias de adaptação e oito dias de colheita de dados. O comportamento ingestivo foi avaliado no $14^{\circ}$ e $15^{\circ}$ dias, o tamanho médio das partículas no $17^{\circ}$ dia, as frações não degradáveis da MS e FDN do feno de tifton 85 foram avaliadas do $18^{\circ}$ ao $20^{\circ}$ dia. Não foram encontrados efeitos para as variáveis analisadas. A inclusão de gérmen integral de milho substituindo o grão de milho em até $26,9 \%$ e com o nível de até $5,1 \%$ de lipídeos na dieta de vacas lactantes pode ocorrer sem afetar o comportamento desses animais.
\end{abstract}

Palavras-chave: ingestão; extrato etéreo; ócio; ruminação; vacas leiteiras.

\begin{abstract}
The objective of this study was to evaluate the inclusion of corn germ meal (CGM) to replace the corn grain ground in the diet of lactating cows, on ingestive behavior, mean particle size, and non-degradable fraction. Five fistulated dairy cows, multiparous, with approximately 100 days of lactation were used, with an average body weight of $490 \mathrm{~kg}$. The treatments were: $0.0 ; 6.7 ; 13.5 ; 20.1$, and $26.9 \%$ CGM to replace the corn grain ground. The experimental design used was a $5 \times 5$ Latin square. There were five periods of 21 days each, with 13 days of adaptation and eight days of data collection. Ingestive behavior was evaluated on days 14 and 15, mean particle size on day 17, non-degradable fractions of DM and NDF of tifton 85 hay were evaluated from the $18^{\text {th }}$ to the $20^{\text {th }}$ day. No effects were found for the analyzed variables. The inclusion of whole corn germ replacing corn grain by up to $26.9 \%$ and the level of up to $5.1 \%$ of lipids in the lactating cows' diet can occur without affecting the behavior of these animals.
\end{abstract}

Keywords: dairy cows; idleness; ingestion; ethereal extract; rumination.

\section{Introdução}

O conhecimento sobre o comportamento manejo alimentar do rebanho que promova ingestivo de vacas lactantes pode ser uma aumento da produtividade animal.

ferramenta para a implantação de uma estratégia de 
A caracterização do comportamento ingestivo se dá através da distribuição desuniforme de uma sucessão de padrões definidos e discretos de atividades, comumente classificadas como ingestão, ruminação e descanso ou ócio (Penning et al., 1991). Para Bezerra et al. (2002), esses padrões podem sofrer influência de diversos fatores de natureza alimentar, como a composição dos alimentos e a forma física com que estes são fornecidos. Segundo Mertens (1994), a aceitabilidade, textura e aparência visual além das interações podem influenciar na ingestão do alimento.

Os ruminantes possuem elevada capacidade de utilização de coprodutos, entretanto as propriedades físicas e químicas dos coprodutos diferem das plantas forrageiras, o que torna sua degradação e passagem pelo trato gastrintestinal diferente, podendo afetar o comportamento ingestivo, que é influenciado pela estrutura física e pela composição química das dietas (Carvalho et al., 2004).

A adição de gordura na alimentação de vacas leiteiras surge como alternativa para elevar o nível energético da dieta, sem aumentar a ingestão de carboidratos não estruturais e sem diminuir a ingestão de fibra (Salla et al., 2003).

O gérmen integral de milho (GIM) é um coproduto obtido por meio da degerminação do grão de milho por via úmida (Lima et al., 2012) o que torna esse coproduto interessante é o seu teor de gordura alto (Brito et al., 2005).

Por ser usado na formulação de rações é indicado para bovinos com aptidão de leite e carne devido à energia, proteína, fibras e baixo teor de amido em comparação ao milho grão (Abdelqader, 2009). A principal vantagem do uso de GIM é a maximização da ingestão calórica, essencial para manutenção da produção e da condição corporal dos animais.

O uso de elevados níveis de gordura na dieta de vacas lactante pode limitas a ingestão de matéria seca (IMS). A IMS é o principal fator que afeta o desempenho animal e é de fundamental importância em nutrição, porque determina a quantidade de nutrientes disponíveis para manutenção da vida e a produção de um animal. Harvatine e Allen (2006) verificaram que a inclusão de $8 \%$ de ácidos graxos na MS da dieta de vacas leiteiras, reduz a IMS.

O objetivo deste estudo foi avaliar os efeitos da inclusão do GIM em substituição ao milho moído, sobre o comportamento ingestivo dos animais, tamanho médio da partícula das dietas e a fração não degradável do feno de tifton.

\section{Material e Métodos}

O experimento foi conduzido no Setor de Bovinocultura do Instituto Federal Goiano Câmpus Ceres, no município de Ceres-GO, a $15^{\circ}$ $21^{\prime} 02,5^{\prime \prime} \mathrm{S}$ e $49^{\circ} 35^{\prime} 53,8^{\prime}$ ' W Gr. Foram utilizadas cinco vacas mestiças, multíparas, com peso médio de $490 \mathrm{~kg}$ de peso corporal e aproximadamente 100 dias de lactação, fistuladas no rúmen e distribuídas em um quadrado latino 5 x 5 .

As vacas foram mantidas confinadas em baias individuais, com comedouros e bebedouros $\mathrm{e}$ área de $48 \mathrm{~m}^{2}$, cobertas por telha de barro na linha central do comedouro e sombrite $70 \%$ na área de descanso. As baias possuíam $50 \%$ do piso de bloquete, sobre o qual foi colocada areia, com a finalidade de servir de cama e o restante do piso era de chão batido. A temperatura ambiente foi mensurada diariamente com auxílio de um termômetro digital localizado na baia do centro e a umidade relativa do ar com o auxílio da estação meteorológica localizada no IF Goiano - Câmpus Ceres. Ao longo do experimento foram encontrados os seguintes valores para temperatura: mínima $15,6^{\circ} \mathrm{C}$; média de $25,7^{\circ} \mathrm{C}$ e máxima de $35,9^{\circ} \mathrm{C}$ e umidade relativa do ar média de $55,4 \%$.

O período experimental foi de 105 dias com cinco períodos de 21 dias, sendo 13 dias de adaptação e oito de coleta de dados. Os tratamentos experimentais consistiram de níveis crescentes de extrato etéreo nas dietas a partir da substituição do milho moído por gérmen integral de milho $(0 ; 6,7$; 13,5; 20,1 e 26,9\%, na matéria seca).

As dietas experimentais foram formuladas utilizando como referência o NRC (2001) para atender as necessidades de vacas com $490 \mathrm{~kg}$ de peso corporal, 100 dias de lactação e produção média de $26 \mathrm{~kg}$ de leite/dia, com 3,8\% de gordura e 3,3\% de proteína no leite de forma que fossem isonitrogenadas e isofibrosas. A composição química dos ingredientes das dietas está na Tabela 1. A proporção dos ingredientes e composição química das dietas experimentais estão descritas na Tabela 2.

As dietas foram fornecidas duas vezes por dia às $8 \mathrm{~h} 00 \mathrm{~m}$ e $16 \mathrm{~h} 00 \mathrm{~m}$, na forma de mistura completa, tendo como volumoso a silagem de milho, sendo oferecidos $40 \%$ pela manhã e $60 \%$ à tarde, em quantidade que assegurasse consumo à vontade, com sobras de no máximo $10 \%$ do total oferecido. 
das análises, as amostras foram descongeladas em temperatura ambiente e avaliadas utilizando separador de partículas modelo Penn State (Particle Size Separador, University Park, PA). As amostras foram colocadas individualmente sobre a peneira de maior diâmetro, e submetida a sequências de cinco movimentos horizontais, em que a cada sequência de movimentos, as peneiras foram submetidas à rotação de $90^{\circ}$. As frações retidas nas peneiras acima de $19 \mathrm{~mm}, 8 \mathrm{~mm}, 1,18 \mathrm{~mm}$ e menor que $1,18 \mathrm{~mm}$ foram transferidas para bandejas $\mathrm{e}$ pesadas para determinação do tamanho médio das partículas com auxílio do software Particle Size Analysis da Universidade Estadual da Pensilvânia - EUA (2012).

As frações não degradadas da MS e da FDN foram determinadas a fim de verificar alterações sofridas pela inclusão do GIM nas dietas experimentais, cuja determinação foi adaptada de Ruiz et al. (2002), sendo utilizado como padrão o feno de Tifton 85 , com a seguinte composição química da MS: 89,20\% de MS, 7,20\% de PB, $9,60 \%$ de $\mathrm{MM}$ e $80,80 \%$ de FDN. O feno foi incubado no rúmen de cada animal utilizando a técnica das sacolas de náilon, confeccionadas segundo as recomendações propostas por Nocek (1988), do $18^{\circ}$ ao $20^{\circ}$ dia de cada período experimental.

As amostras foram acondicionadas em saquinhos de náilon $20 \times 12,5 \mathrm{~cm}$, com porosidade média de $50 \mu \mathrm{m}$, contendo $5 \mathrm{~g}$ de feno moído em peneira de $5 \mathrm{~mm}$, mantendo a relação de 20 $\mathrm{mg} / \mathrm{cm}^{2}$, sendo incubadas em triplicata, em ordem decrescente nos tempos 48 e $24 \mathrm{~h}$. Todos os saquinhos foram acondicionados em uma sacola de náilon de $40 \times 25 \mathrm{~cm}$ e colocada no rúmen via cânula.

Ao final de cada tempo de incubação, todas as amostras foram retiradas e imediatamente colocadas em um recipiente contendo água fria a fim de interromper o ataque microbiano frente ao substrato. Em seguida, os saquinhos contendo as amostras de $0 \mathrm{~h}$ foram colocados juntamente com os saquinhos dos demais tempos em um recipiente de plástico para serem lavados em água corrente, para retirada de fragmentos de conteúdo ruminal, até que a água da lavagem fluísse de forma incolor. Assim, os mesmos foram congelados para posteriores análises da MS e FDN.

Ao final do experimento, os saquinhos foram descongeladas em temperatura ambiente $\mathrm{e}$ colocadas em estufa de ventilação forçada a $60^{\circ} \mathrm{C}$ por $72 \mathrm{~h}$. Após a secagem, as amostras foram pesadas e formadas amostras compostas no tempo e tratamento, as quais foram moídas em moinho do tipo Willey, em peneiras com crivo de $1 \mathrm{~mm}$ e utilizadas para determinação da MS e FDN. Os dados para a média da fração não degradável da MS e FDN foram calculados com base na média da razão entre o peso do resíduo após a incubação e o peso do resíduo incubado $* 100$ e o resultado dividido pela fração não degradável no tempo $0 \mathrm{~h}$ $* 100$.

$\mathrm{O}$ experimento instalado foi delineado em quadrado latino, com o modelo estatístico: $Y_{\mathrm{ijk}}=\mu$ $+T_{i}+A_{j}+P_{k}+e_{i j k}$, em que: $Y_{i j k}=$ valor observado no tratamento $\mathrm{i}$, animal $\mathrm{j}$ e período $\mathrm{k} ; \mu=$ média geral do experimento; $\mathrm{T}_{\mathrm{i}}=$ efeito do tratamento $\mathrm{i}$; $\mathrm{A}_{\mathrm{j}}=$ efeito do animal $\mathrm{j} ; \mathrm{P}_{\mathrm{k}}=$ efeito do período $\mathrm{k} ; \mathrm{e}_{\mathrm{ijk}}$ $=$ efeito do erro aleatório associado a observação $\mathrm{Y} / \mathrm{ijk}$.

As variáveis, comportamento ingestivo dos animais e da fração não degradável do feno de tifton foram avaliadas através da regressão polinomial, tendo os tratamentos quantitativo (GIM 0, GIM 6,7; GIM13,5; GIM 20,1 e GIM $26,9 \%)$ como variável resposta. Os modelos de regressão foram submetidos à análise de variância considerando o delineamento em quadrado latino, com teste para a falta de ajuste. Selecionou-se modelos onde os regressores foram significativos e a falta de ajuste não significativa, adotando-se o nível de significância de 5\%. Todas as análises foram realizadas com auxílio do software $\mathrm{R}$ ( $\mathrm{R}$ Development Core Team, 2013) version 2.15.3 (2013-03-01).

\section{Resultados e Discussão}

Não houve efeito da substituição do milho grão pelo GIM, sobre a ruminação, ingestão, ócio, tempo de mastigação total (TMT), eficiência alimentar (EA) e eficiência da ruminação (ERU) (Tabela 3).

É possível que a ausência do efeito dos lipídios sobre a ruminação, ingestão, ócio, TMT, EA e ERU tenha ocorrido porque os níveis de GIM não alcançaram teores de lipídios capazes de afetar a digestibilidade da FDN, fato esse que não comprometeu o consumo e a digestibilidade da FDN. Palmquist e Mattos (2006) gordura suplementada na dieta de ruminantes em níveis superiores a $5 \%$ da matéria seca, reduz a digestibilidade da fibra. Segundo Campbell et al. (1992), o teor da FDN e o tamanho médio de partícula são alguns dos fatores mais importantes 
ligados ao alimento que interferem no comportamento ingestivo dos ruminantes.

No presente estudo as dietas foram isofibrosas (Tabela 2), o que para Welch e Hooper (1988) explica o tempo despendido com a ruminação, pois a mesma é altamente correlacionada com a FDN na dieta de bovinos. O fato da mastigação estar relacionada com a quantidade de material indigestível ou pouco digestível consumida e com a resistência do material, pois essa e a forma do animal reduzir o tamanho de partículas (Fischer, 1997).

Tabela 3. Comportamento ingestivo de vacas lactantes alimentadas com diferentes níveis de gérmen integral de milho.

\begin{tabular}{|c|c|c|c|c|c|c|c|c|c|}
\hline \multirow{2}{*}{ Variável } & \multicolumn{5}{|c|}{ Níveis de inclusão do GIM (\%) } & \multirow[b]{2}{*}{$\begin{array}{c}\text { CV } \\
(\%)\end{array}$} & \multicolumn{3}{|c|}{ Regressão } \\
\hline & $\mathbf{0}$ & 6,7 & 13,5 & 20,1 & 26,9 & & $\mathbf{P}_{1}$ & $\mathbf{P}_{2}$ & Modelo \\
\hline Ingestão (h/dia) & 5,1 & 4,87 & 4,96 & 4,92 & 5,06 & 7,12 & 0,968 & 0,713 & ns \\
\hline Ócio (h/dia) & 9,83 & 10,5 & 10,1 & 9,76 & 9,85 & 7,1 & 0,494 & 0,383 & $\mathrm{~ns}$ \\
\hline Ruminação (h/dia) & 9,07 & 8,62 & 8,95 & 9,32 & 9,08 & 6,21 & 0,373 & 0,376 & $\mathrm{~ns}$ \\
\hline TMT (h/dia) & 14,2 & 13,5 & 13,9 & 14,2 & 14,2 & 5,08 & 0,494 & 0,383 & ns \\
\hline EAL ( $\mathrm{kg}$ de $\mathrm{MS} / \mathrm{h})$ & 3,96 & 4,00 & 4,13 & 4,28 & 3,93 & 8,93 & 0,702 & 0,431 & $\mathrm{~ns}$ \\
\hline ERU (kg de MS/h) & 2,18 & 2,26 & 2,24 & 2,21 & 2,19 & 5,45 & 0,923 & 0,742 & $\mathrm{~ns}$ \\
\hline
\end{tabular}

GIM: Gérmen integral de milho, TMT: Tempo de mastigação total, EAL: Eficiência de alimentação, ERU: Eficiência de ruminação, $\mathrm{CV}$ : coeficiente de variação, $\mathrm{P}_{1}$ : Probabilidade para efeito do modelo linear, $\mathrm{P}_{2}$ : Probabilidade para falta de ajuste e ns: não significativo.

Para os valores das variáveis ócio, TMT, EAL e ERU resultados semelhantes foram observados por Salla et al. (2003), que trabalhando com vacas lactantes recebendo os tratamentos: controle, sebo bovino, gordura protegida e grão de soja, com 2,08; 5,90; 5,17 e 5,24\% de EE respectivamente, não encontraram efeito dos tratamentos para estas variáveis.

Os eventos ócio, ruminação e ingestão são realizados desuniformemente ao longo das $24 \mathrm{~h}$, caracterizando que os eventos ligados ao comportamento são cíclicos. Entretanto é possível observar que em determinados períodos há maior concentração de tempo e frequência desses eventos (Figura 1). De acordo com Fischer et al. (2002), existem diferenças individuais quanto à duração e à repartição das atividades de ingestão e ruminação, que parecem estar relacionadas ao apetite, às diferenças anatômicas e ao suprimento das exigências energéticas ou repleção ruminal.

A maior frequência do ócio ocorreu após as refeições, ao passo que se concentrou mais uniformemente ao longo dos períodos em relação aos demais eventos (Figura 1A). Para Fischer et al. (1997), o ócio é considerado o tempo que o animal fica sem atividade física, podendo estar deitado ou em pé e relatam que os períodos de ruminação e ócio entre as refeições, tem duração e padrão de distribuição influenciados pelas atividades de ingestão.
Uma maior concentração da ruminação foi observada aproximadamente $3 \mathrm{~h}$ após as refeições e com maior frequência no período noturno (Figura 1B). O tempo gasto em ruminação é normalmente mais prolongado à noite, mas os períodos de ruminação são ritmados também pelo fornecimento de alimento (Pazdiora et al., 2011).

A ingestão é promovida com maior concentração após as dietas serem fornecidas. Tendo sua concentração, mais evidenciada em até duas horas após o fornecimento das refeições (Figura 1C). Para Pazdiora et al. (2011) a frequência do fornecimento da dieta promove maior intensificação na ingestão no momento do fornecimento, mas isso não altera o tempo de ingestão do alimento ao longo do dia.

O tamanho médio das partículas das dietas oferecidas pela manhã, em função do tempo 0,4 e $8 \mathrm{~h}$ após a alimentação das vacas está representado na Figura 2. Verificou-se que a inclusão do GIM não interferiu no tamanho médio das partículas das dietas até $8 \mathrm{~h}$ após o fornecimento da refeição matinal, o que possivelmente contribuiu para não afetar o comportamento ingestivo.

O tamanho médio das partículas pode sofrer seleção dos animais ao longo do tempo de alimentação. De acordo com Leonardi e Armentano (2003), as vacas selecionam os ingredientes presentes na dieta total, tendo preferências pelos grãos em detrimento ao 
volumoso. No comportamento ingestivo de vacas, Devries et al. (2007) relataram que os bovinos podem ingerir partículas menores em detrimento das partículas longas, o que poderia reduzir a ingestão de FDN fisicamente efetiva e aumentar a ingestão da fração de carboidratos não estruturais.
Esta situação proporcionaria alteração na função do rúmen e aumento do risco de deslocamento de abomaso, flutuações na ingestão de alimentos, redução do teor de gordura do leite e na atividade de ruminação.

Tempo em Ócio
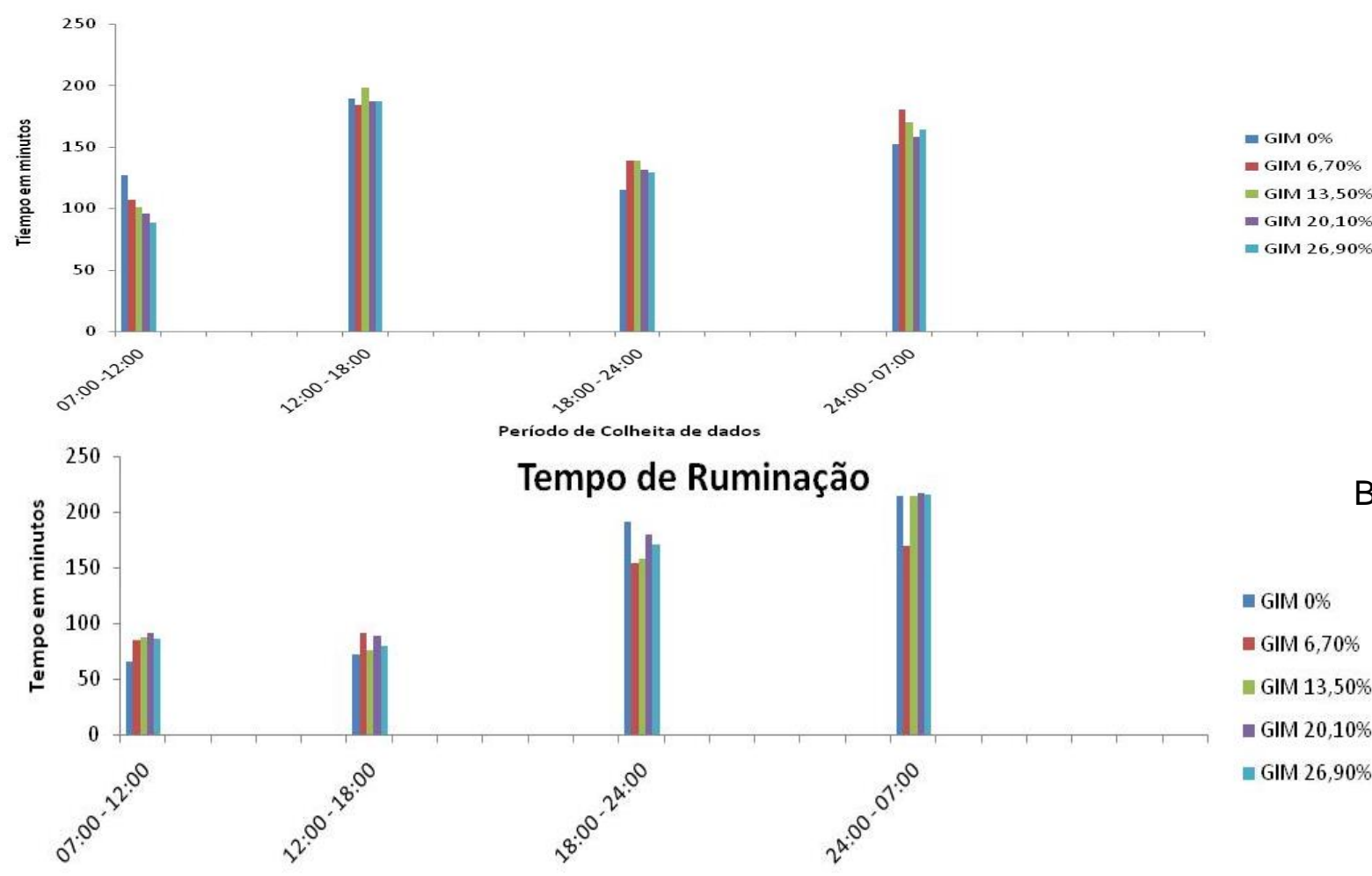

Tempo de Ruminação

B

- GIM $0 \%$

- GIM 6,70\%

- GIM $13,50 \%$

- GIM 20,10\%

- GIM 26,90\%

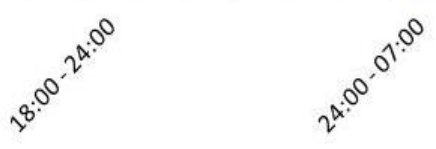

Período de Colheita

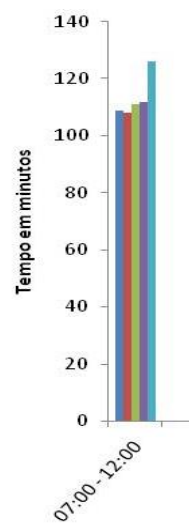

Tempo de Ingestão

Figura 1. (A) Tempo em minutos do evento ócio, (B) Tempo em minutos do evento ruminação e (C) Tempo em minutos do evento ingestão nos tratamentos ao longo de $24 \mathrm{~h}$.

A inclusão do GIM não interferiu na fração não degradável da fibra em detergente neutro (FDN) e matéria seca (MS) do feno de tifton 85 (Tabela 4). Os resultados do presente estudo demonstraram que, aumentando o teor de lipídios provindos do GIM na dieta de vacas lactantes, não há efeito sobre a fração não degradável da FDN e da MS do feno de tifton 85. Estando acordo com os observados por Jobim et al. (2011) em estudo sobre a cinética de degradação ruminal in situ para a MS e a FDN do feno de tifton 85, nos tempos de 24 e 48h após a incubação. 


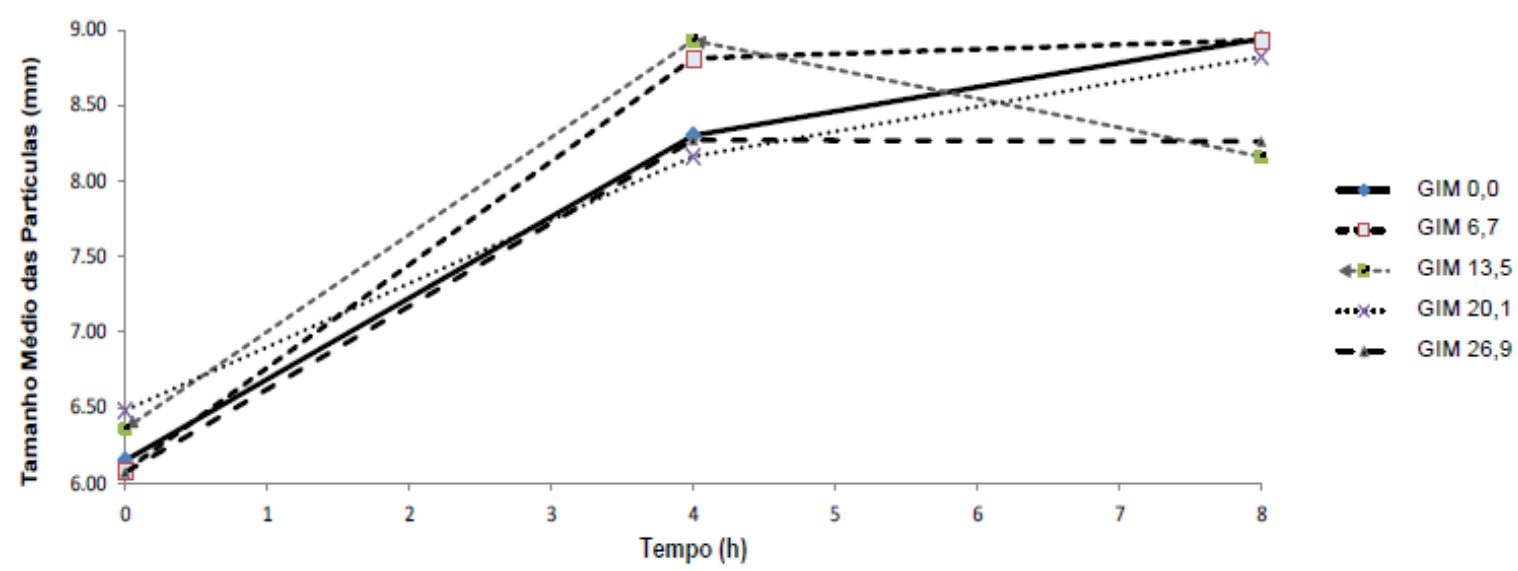

Figura 2. Tamanho médio das partículas oferecidas na dieta de vacas lactantes, em função do tempo de alimentação.

Tabela 4. Percentual da fração não degradável da fibra em detergente neutro e da matéria seca do feno de tifton 85 .

\begin{tabular}{|c|c|c|c|c|c|c|c|c|c|}
\hline \multirow{2}{*}{ Tempo (h) } & \multicolumn{5}{|c|}{ Níveis de inclusão do GIM (\%) } & \multirow{2}{*}{$\begin{array}{l}\text { CV } \\
(\%)\end{array}$} & \multicolumn{3}{|c|}{ Regressão } \\
\hline & $\mathbf{0}$ & 6,7 & 13,5 & 20,1 & 26,9 & & P1 & P2 & Modelo \\
\hline \multicolumn{10}{|c|}{ Fração não degradável da fibra em detergente neutro } \\
\hline 24 & 72,02 & 80,4 & 79,7 & 77,48 & 77 & 13,18 & 0,649 & 0,651 & ns \\
\hline 48 & 50,36 & 55,94 & 60,04 & 58,4 & 55,32 & 17,68 & 0,412 & 0,621 & $\mathrm{~ns}$ \\
\hline \multicolumn{10}{|c|}{ Fração não degradável da matéria seca } \\
\hline 24 & 71,21 & 74,87 & 78,47 & 77,77 & 79,9 & 8,22 & 0,061 & 0,981 & $\mathrm{~ns}$ \\
\hline 48 & 52,04 & 57,65 & 58,7 & 59,45 & 57,68 & 12,83 & 0,256 & 0,703 & ns \\
\hline
\end{tabular}

GIM: Gérmen integral de milho, $\mathrm{P}_{1}$ : probabilidade do modelo linear, $\mathrm{P}_{2}$ : probabilidade para a falta de ajuste, CV: coeficiente de variação e ns: não significativo.

A inclusão de $26,9 \%$ de GIM não proporcionou elevação suficiente no teor de lipídeos das dietas para promover efeito sobre o ambiente ruminal e, consequentemente, comprometer a digestibilidade da FDN e MS, uma vez que, o aumento dos teores de lipídios insaturados provoca efeito sobre a taxa de degradação, em especial ao desaparecimento da fibra, já que ácidos graxos insaturados são tóxicos aos microrganismos ruminais e podem diminuir a degradação de fibra. Todavia, Palmquist e Mattos (2006) relatam que valores próximos de $5 \%$ de $\mathrm{EE}$ na MS de dietas para bovinos não causa efeito sobre a degradação, o que pôde ser observado neste estudo.

\section{Conclusão}

O nível de até $5,1 \%$ de lipídeos na dieta não afeta o comportamento ingestivo de vacas em lactação.

\section{Conflito de Interesse}

Os autores declaram não existir conflito de interesse.

\section{Comitê de Ética}

Aprovado pelo Comitê de Ética em Pesquisa Animal do Instituto Federal Goiano, sob o número 003/2011.

\section{Agradecimentos}

Os autores agradecem ao apoio recebido do CNPq, GEM Alimentos, Master Vet e ao IFGoiano.

\section{Referências}

Abdelqader, M.M.; Hippen, A.R.; Kalscheur, K.F.; Schingoethe, D.J.; Karges, K.; Gibson, M.L. Evaluation of corn germ from ethanol production as an alternative fat source in dairy cow diets. Journal of Dairy Science, 92(3): 1023-1037, 2009.

Bezerra, E.S.; Queiroz, A.C.; Maldonado, F. Efeito do perfil granulométrico das partículas dietéticas sobre parâmetros de desempenho de vacas leiteiras em lactação. Revista Brasileira de Zootecnia, 31(3): 1511-1520, 2002.

Bürger, P.J.; Pereira, J.C.; Queiroz, A.C.; Silva, J.F.C.; Valadares Filho, S.C.; Cecon, P.R.; Casali, A.D.P. Comportamento ingestivo em 
bezerros holandeses alimentados com dietas contendo diferentes níveis de concentrado. Revista Brasileira de Zootecnia, 29(1):236$242,2000$.

Brito, A.B.; Stringhini, J.H.; Belem, L.M.; Xavier, S.A.G.; Leandro, N.S.M.; Café, M.B. Desempenho e qualidade dos ovos de poedeiras comerciais de 30 a 64 semanas de idade consumindo gérmen integral de milho. Acta Scientiarum. Animal Sciences. 27(1): 29-34, 2005.

Campbell, C.P.; Marshall, S. A.; Mandell, I. B.; Wilton, J. B. Effects of source of dietary neutral detergent fiber on chewing behavior in beef cattle fed pelleted concentrates with or without supplemental roughage. Journal of Animal Science, 70(7): 894-903, 1992.

Carvalho, G.G.P.; Pires, A.J.V.; Silva, F.F.; Veloso, C.M.; Silva, R.R.; Silva, H.G.O.; Bonomo, P.; Mendonça, S. S.Comportamento ingestivo de cabras leiteiras alimentadas com farelo de cacau ou torta de dendê. Pesquisa Agropecuária Brasileira, 39(09): 919-925, 2004.

Devries, T.J.; Beauchemin, K.A.; Keyserlingk, M.A.G. Dietary forage concentration affects the feed sorting behavior of lactating dairy cows. Journal of Dairy Science, 90(12): 5572-5579, 2007.

Fischer, V.; Deswysen, A.G.; Despres, P. Comportamento ingestivo de ovinos recebendo dieta a base de feno durante um período de seis meses. Revista Brasileira de Zootecnia, 26(5): 1032-1038, 1997.

Fischer, V.; Deswysen, A.G.; Dutilleul, P.; Boever, J. Padrões da distribuição nictameral do comportamento ingestivo de vacas leiteiras, ao início e ao final da lactação, alimentadas com dieta à base de silagem de milho. Revista Brasileira de Zootecnia, 31(5): 2129-2138, 2002.

Hall, M.B. Neutral detergent-soluble carbohydrates: nutritional relevance and analysis, a laboratory manual. Gainesville: University of Florida, (Extension Bulletin, 339). 2000. 42p.

Harvatine, K. J.; Allen, M. S. Effects of fatty acids supplements on milk yield and energy balance of lactating dairy cows. Journal of Dairy Science, 89(3): 1081-1091, 2006.

Jobim, C.C.; Ferreira, G.A.; Bumbieris Junior, V.H.; Calixto Junior, M.; Santos, G.T. Cinética de degradação ruminal dos fenos de alfafa e Tifton-85 e da silagem de milho. Semina: Ciências Agrárias, 32(2): 747-758, 2011.

Kononoff, P.J.; Heinrichs, A.J.; Buckmaster, D.R. Modification of the Penn State Forage and Total Mixed Ration Particle Separator and the Effects of Moisture Content on its Measurements. Journal of Dairy Science, 86(5): 1858-1863, 2003.

Leonardi, C.; Armentano, L.E. Effect of quantity, quality, and length of alfalfa hay on selective consumption by dairy cows. Journal of Dairy Science, 86(2): 557-564, 2003.

Lima, M.B.; Rabello, C.B.V.; Silva, E.P.; Lima, R.B.; Arruda, E.M.F.; Albino, L.F.T. Effect of broiler chicken age on ileal digestibility of corn germ meal. Acta Scientiarum. Animal Sciences. 34(2): 137-141, 2012.

Mertens, D.R. Regulation of forage intake. In: Forage quality, evaluation and utilization. American Society of Agronomy, 450-493, 1994.

National Research Council. Nutrient requirements of the dairy cattle. $7^{\text {th }}$ ed., D.C., Washington, D.C.: National Academy Press. 2001. 363 p.

Nocek, J.E. In situ and others methods to estimate ruminal protein and energy digestibility. Journal Dairy Science, 71(8): 2051-2069, 1988.

Palmquist, D.L.; Mattos, W.R.S. Metabolismo de lipídeos. In: Berchieli, T.T.; Pires, A.V.; Oliveira, S.G. (Eds.). Nutrição de ruminantes. Jaboticabal: Funep, 2006, p.287310.

Pazdiora, R.D.; Brondani, I.L.; Silveira, M.F.; Arboitte, M.Z.; Cattelam, J.; Paula, P.C. Efeitos da frequência de fornecimento do volumoso e concentrado no comportamento ingestivo de vacas e novilhas em confinamento. Revista Brasileira de Zootecnia, 40(10): 2244-2251, 2011.

Penning, P.D.; Rook, A.; Orr, R.J. Patterns of ingestive behavior of sheep continuously stocked on monocultures of ryegrass or white clover. Animal Science, 31(3-4): 237-250, 1991.

$\mathrm{R}$ development core team. $\mathrm{R}$ : A language and environment for statistical computing. $R$ Foundation for Statistical Computing, 2013. Disponível em: <http://www.r-project.org>. Acesso: 19 abr. 2013. 
Ruiz, R.; Tedeschi, L.O.; Marini, J.C.;Fox, D.G.; Pell, A.N.; Jarvis, G.; Russell, J.B. The Effect of a Ruminal Nitrogen (N) Deficiency in Dairy Cows: Evaluation of the Cornell Net Carbohydrate and Protein System Ruminal N Deficiency Adjustment. Journal of Dairy Science, 85(11): 2986-2999, 2002.

Salla, L.E.; Fischer, V.; Ferreira, E.X.; Moreno, C.B.; Stumpf Junior, W. Duarte, L.M.A. Comportamento ingestivo de vacas Jersey alimentadas com dietas contendo diferentes fontes de gordura nos primeiros 100 dias de lactação. Revista Brasileira de Zootecnia, 32(3): 683-689, 2003.

Silva, D.J.; Queiroz, A.C.Análise de alimentos: métodos químicos e biológicos. Viçosa: UFV/ Imprensa Universitária, 2002. 239p.

Sniffen, C.J.; O`Connor, J.D.; Van Soest, P.S.A net carbohydrate and protein Availability. Journal of Animal Science, v.70, n.11, p.3562-3577, 1992.

Welch, J.G.; Hooper, A.P. Ingestion of feed and water. In: Church, D.C. The ruminant animal: digestive physiology and nutrition. Englewood Cliffs: Reston, 1988. p. 108-116. 